\title{
Evidence on the Efficient Market Hypothesis from 44 Global Financial Market Indexes
}

\author{
Huijian Dong, ${ }^{1}$ Helen M. Bowers, ${ }^{2}$ and William R. Latham ${ }^{3}$ \\ ${ }^{1}$ Department of Business Administration, College of Business, Pacific University, Forest Grove, OR 97116, USA \\ ${ }^{2}$ Department of Finance, Alfred Lerner College of Business \& Economics, University of Delaware, Newark, DE 19716, USA \\ ${ }^{3}$ Department of Economics, Alfred Lerner College of Business \& Economics, University of Delaware, Newark, DE 19716, USA \\ Correspondence should be addressed to Huijian Dong; hdong@pacificu.edu
}

Received 5 July 2013; Revised 3 September 2013; Accepted 12 September 2013

Academic Editor: Thanasis Stengos

Copyright (c) 2013 Huijian Dong et al. This is an open access article distributed under the Creative Commons Attribution License, which permits unrestricted use, distribution, and reproduction in any medium, provided the original work is properly cited.

\begin{abstract}
This paper employs Granger causality tests to identify the impacts of historical information from global financial markets on their current levels in 30-day windows. The dataset consists primarily of the daily index levels of the (1) open, (2) closed, (3) intraday high, (4) intraday low, and (5) trading volume series for the world's 37 most influential equity market indexes, two crude oil prices, a gold price, and four major money market prices in the United States are used as control groups. Our results indicate a persistent impact of historical information from global markets on their current levels, and this impact duplicates itself in a cyclical pattern consistently over decades. Such persistence in the patterns causes some market indexes to be upgraded to global or regional market leaders. These findings can be interpreted as constituting violations of the weak-form efficient market hypothesis. The results also reveal recursive impacts of information in these markets and the existence of an information digestion effect.
\end{abstract}

\section{Introduction}

This paper examines the causal connections from crosscountry historical levels of global financial markets to their current levels. A number of prior studies have demonstrated the existence of such cross-country connections using panel data from a limited number of equity markets and examining the causality only for current levels of global stock markets. When a significant causal relation in such tests is detected, the semistrong form of the Efficient Market Hypothesis (EMH) [1] is violated.

However, because the semistrong form EMH is a subset of the weak-form EMH, one can begin with the examination of the impacts of historical information. Specifically, if crossmarket historical levels of global financial markets indexes can affect their current levels, the market is not even weakform efficient so it cannot be semistrong form efficient. Therefore, the primary purpose of this paper is to identify the role of the historical levels of the major indexes and prices in global financial markets and to test the weak-form EMH. The second major purpose is to investigate how investors digest different information from various series of market indexes.

Studies in this field generally use one or more of three methods: Granger causality [2], cointegration [3], and various types of autoregressive conditional heteroscedasticity (ARCH) [4]. Researchers in this field employ various terms for the phenomenon of global financial markets being connected endogenously, including "contagion" [5], "integration" [6], "comovement" [7], "spillover" [8], "interdependence" [9], "interaction" [10], "linkages" [11], and "correlation" [12].

Contagion and spillover refer to causal relations in either market prices or market volatilities, and, therefore, either a Granger causality model or an ARCH model would be proper specification for testing the EMH. Integration and comovement refer to cointegration relations at the market price level, and, therefore, cointegration tests are an appropriate method for testing the EMH. The other terms, including "interaction" and "linkages," are less well defined so, these terms cannot be easily tied to a particular method. Although correlation coefficients are, strictly speaking, measures of 
statistical correlation, their computation reveals neither the causal sequence nor the cointegration relations in financial markets.

Several other studies, such as Boyer [13] and Jawadi et al. [14], have also used causality models to test for the mutual impacts of global financial markets at current levels. However, in this paper we focus on the impacts of the levels of both historical and current international markets. All the analyses are performed in a 30-day test window to measure day-byday impacts and to capture any attenuation of the influence if such attenuation exists. Based on the raw test results, we also develop a new method for detecting and identifying the cyclical pattern of historical impacts.

To reach more robust conclusions across countries and markets than other studies, we examine daily data for five measures ((1) open, (2) closed, (3) intraday high, (4) intraday low, and (5) volume) for 37 major world equity market indexes as well as for two crude oil prices, and the price of gold. We also include in the analysis four U.S. Treasury interest rates which track both long term and short term fixed income markets. This yields a total of 204 series to use in the analysis. For each series we use all the observations available between October 1, 1928, and August 11, 2011. To sum up, 204 time series are used in the causality tests in our study. This cross-country and cross-market dataset is by far the largest that has been used to test related hypotheses. Other similar studies with large datasets include Beine et al. [9], with 17 countries; Cappiello et al. [15], with 21 countries; and Valadkhani and Chancharat [16], with 16 countries.

The results of the causality tests and regressions in this paper confirm the existence of persistent, cyclical impacts from global markets' historical levels to their current performance. In the 30-day test window, $21.53 \%$ of the historical market levels significantly affect the current closed levels in the world markets; $24.33 \%$ of the historical market levels significantly affect the current intraday highs; $23.04 \%$ affect the intraday lows, $25.52 \%$ affect the open levels; and $44.27 \%$ affect trading volumes. These statistically significant impacts of historical information on current levels violate the weakform EMH.

The results also reject the notion of an "information digestion" effect. This hypothesis refers to the belief that older historical information will have a less influential impact on the current market. In other words, the value of information has been hypothesized to strictly decrease with time. The idea is intuitively appealing: as investors receive new market messages they will tend to discount older news and do so more as time moves on. However, our results show that, except for a sharp decrease in the impact of information from the current day to one day lagged, there is no further decrease after the first lagged operating day. In fact, the 30 operating days in the test window show a cyclical pattern in their impact powers, rather than the decreasing pattern assumed by the information digestion effect and certainly not the zero impact implied by the weak-form EMH. In our results the cyclical pattern of impacts of the world's major indexes in the 30-day window on the current closed levels indicates that after approximately 5.5 lagged operating days, the impact peak recurs. Similar recurring impacts are observed for the current open, high, and low levels, but not to the trading volume levels. This five-day pattern may be reflecting a weekly seasonal effect in the impacts.

In addition, we use the results to identify the most important global and regional financial markets by ranking the average probabilities of significant causal relations for the 204 series. Our results indicate that the ten most influential series, in rank order from most influential to least, are the crude oil price in New York, the North Sea Brent crude oil price, the equity market indexes in Mexico, Turkey, Australia, Russia, Germany, Sweden, the U.S. (the Dow Jones index), and Hong Kong, and the world gold price. Thus the commodity series are the most consistent overall market leaders. Among the country indexes, there are several regional leaders: the U.S. and Mexico lead in the Americas, Germany leads in Europe, Australia and Hong Kong lead in Asia, and Turkey leads in the Middle East. The causality tests indicate significance mostly at the $1 \%$ level, and altering the required significance level plays a very limited role in affecting the conclusions. Furthermore, the results are stable over time.

Many similar studies have drawn conclusions on specific causal relations among markets. For example, Valadkhani and Chancharat [16] show that in the short term, the equity markets in Hong Kong and the U.K. will affect the market in Thailand without any feedback. Our results are consistent with their conclusion. Morana and Beltratti [17] find that stock markets in the U.S., the U.K., Germany, and Japan have a high level of integration. They find that the linkage is stronger for the U.S. and European markets than it is for the Japanese market. However, our results show that the link between the U.S. market and the European markets is limited to only the Central Europe area; Syriopoulos [18] suggests that Central European markets tend to display stronger linkages with their mature counterparts, whereas the U.S. market holds a world leading influential role. While our paper also supports the strong linkages in the Central Europe area, the world leader role is taken by the New York and North Sea Crude Oil prices, rather than the Dow Jones Industrial Average .

\section{Data}

Measuring causal relations in markets using individual stock or bond prices is not feasible in practice in a study of the scope of this one because each of the markets we study has many individual stock listings. Our measure of each financial market's aggregate price level is the comprehensive index for the market. The most widely used indexes in different economies usually contain the major industries and representative stocks and thus are good proxies for stock price levels in the entire market. In this paper we examine 204 data series. We use the (1) daily open, (2) closed, (3) intraday high, (4) intraday low, and (5) volume data for 40 series (37 major global equity market indexes, two crude oil indexes "the New York Futures Exchange price and U.K. North Sea Brent price", and the price of gold). In addition we use four fundamental U.S. Treasury interest rates (13-week, 5-year, 10-year, and 30year T-bonds).

Depending on availability, the starting dates of the observations for the different indexes vary from October 1, 1928, to 
recent decades. All the data series end on August 11, 2011. We drop the very rare observations from Saturdays and Sundays market but include occasional holidays because the latter are not synchronous globally. The data series vary in numbers of observations from 1,311 (for the Madrid General Index) to 20,817 (for the Dow). To sum up, 204 time series and more than 1 million observations are involved in the causality tests in our study. All the trading volume data are based on the domestic currency in the market. The crude oil prices and gold prices are based on the spot value of the U.S. dollar. The data are described in more detail in Table 1.

The indexes selected are from the Wall Street Journal daily report. In many cases, multiple indexes exist in an equity market, such as the three major indexes published for the Tokyo Stock Exchange: NIKKEI 225, NIKKEI 300, and NIKKEI 500. However, only NIKKE 225 is cited in WSJ. In this case, we use it as the representative index for Japan. In Spain, India, and the United States, more than one series may be regarded as representative, such as the DOW and NASDAQ in the U.S.. Therefore, we include more than one index for these economies. The lengths of the time series differ, as we attempt to maximize the degrees of freedom of the VAR model. The cointegration and causality regressions are performed at the maximum length for each variable. We do not consider cross-market comparisons because of the variety of data availability.

A number of studies in this field, such as [19-21] Worthington et al. [22], and Valadkhani and Chancharat [16], use the Morgan Stanley Capital International (MSCI) indexes. MSCI is not used in this paper because (1) intuitively, investors rely on their observations of the levels of the actual indexes and prices of individual stocks rather than on the level of the MSCI index when investment decisions are made; (2) the MSCI index excludes dual-listed stocks from the index portfolio, and such stocks may be significant determinants of the causality of stock prices studied in this paper; and (3) all MSCI indexes are denominated in U.S. dollars and this process separates the effects of currency exchange rates from causality in stock prices. In addition, transaction costs in real foreign exchange markets, such as those derived from the Bid-Ask spread inventory risk bearing, and information effect costs are not considered in the MSCI index. However, such costs will affect market index movements, and our study needs to incorporate these effects.

It is generally believed that datasets with higher frequencies can help capture more precisely the effects of contagions and interdependences. Recent studies support this view. For example, Wongswan [23] concludes that macroeconomic information announcements in developed economies have an impact on emerging economy equity market volatility that only lasts about 30 minutes on average. This indicates that studies based on lower frequency data may fail to capture the correlations. However, Hakkio and Rush [24] found that, although increasing the frequency of data can add degrees of freedom, it is otherwise not important to increase the frequency of data from daily to intraday. They suggest that market linkages are essentially long-run relations and the key requirement is a long time span of data. Thus we use daily data for a long time span.
Additional arguments against using intraday data are based on the belief that intraday data will introduce unnecessary noise. Morana [25], Baharumshah et al. [26], and Worthington et al. [22] support this view, and they also claim that the influence of some economic shocks will only be significant after a longer period of time. We use daily data to avoid possible noise effects and use long run series to capture all the effects of shocks.

\section{Method}

Previous studies, such as those of M. Eryiǧit and R. Eryiǧit [12] and Goetzmann et al. [27], have used correlation coefficients to test for causality in global financial markets. However, correlation does not necessarily imply causation, especially the kind of causation that [28] introduced and which is now widely accepted as the appropriate empirical definition. ${ }^{2}$ The concept of causality used in this paper is Granger causality.

We perform the causality tests in paired samples. For a bivariate linear autoregressive model with pairwise variables $X_{1}$ and $X_{2}$, the test regression is

$$
\begin{aligned}
& X_{1}(t)=\sum_{j=1}^{P} A_{11, j} X_{1}(t-j)+\sum_{j=1}^{P} A_{12, j} X_{2}(t-j)+E_{1}(t), \\
& X_{2}(t)=\sum_{j=1}^{P} A_{21, j} X_{1}(t-j)+\sum_{j=1}^{P} A_{22, j} X_{2}(t-j)+E_{2}(t) .
\end{aligned}
$$

$P$ in the regression equations is the maximum number of lags included, and the matrix $A$ is the plain vanilla VAR coefficient. $E_{.}(t)$ is the regression residual. If the variance of $E$. $(t)$ is improved by adding $X_{1}$ or $X_{2}$, it implies that $X_{1}$ or $X_{2}$ Granger causes $X_{2}$ or $X_{1}$. The way to detect such improvement is by testing whether, for example, the coefficients carried by $A_{12}$ are jointly different from zero. If the null hypothesis of $A_{12}=0$ is rejected significantly by the $F$ test, $X_{2}$ Granger causes $X_{1}$. We use the Bayesian Information Criterion (BIC) to determine the number of lags.

A VAR model embedded with seasonality is another potentially reasonable instrument that assists in exploring the cyclical pattern of historical financial market information impacts. However, as there is no theoretical basis to assume the length of the cyclical period, the settings of that model remain unclear. It is also not feasible to compute the significance levels of the seasonal VAR models for all different possible cyclical periods. In addition, as our study focuses on the impact of historical asset prices on the current prices, rather than the impact of historical volatilities on the current risk, we do not adopt the ARCH model, which would be a more adequate measure of the spillover of the variances of asset returns.

To better address the comovement pattern in the global financial market, we also perform the VECM based cointegration test. The cointegration test follows the results of the 
TABLE 1: Dataset summary.

\begin{tabular}{|c|c|c|c|c|}
\hline Aggregate series & Markets & Indexes & Start date & Sample size \\
\hline ARG & Argentina & MerVal Index & $10 / 08 / 96$ & 3673 \\
\hline AUS & Australia & All Ordinaries Index & 08/03/84 & 6844 \\
\hline AUT & Austria & ATX Index & $11 / 11 / 92$ & 4645 \\
\hline BEL & Belgium & BEL-20 Index & $02 / 11 / 05$ & 1506 \\
\hline BRA & Brazil & Bovespa Index & $04 / 27 / 93$ & 4533 \\
\hline CAN & Canada & S\&P TSX Composite Index & 01/03/00 & 2932 \\
\hline $\mathrm{CHE}$ & Switzerland & Swiss Market Index & $11 / 09 / 90$ & 5240 \\
\hline $\mathrm{CHL}$ & Chile & IPSA Index & $01 / 10 / 03$ & 1984 \\
\hline $\mathrm{CHN}$ & China & Shanghai Composite Index & $01 / 04 / 00$ & 2979 \\
\hline DEU & Germany & DAX Index & $11 / 26 / 90$ & 5245 \\
\hline DNK & Denmark & OMX COPENHAGEN 20 Index & $01 / 03 / 00$ & 2961 \\
\hline ESP1 & Spain & Madrid General Index & $06 / 29 / 06$ & 1311 \\
\hline ESP2 & Spain & IBEX 35 Index & $02 / 15 / 93$ & 4625 \\
\hline FRA & France & CAC 40 Index & 03/01/90 & 5433 \\
\hline GBR & UK & FTSE 100 Index & $04 / 02 / 84$ & 6919 \\
\hline GOL & - & World Gold Price Index & $12 / 29 / 78$ & 8510 \\
\hline HGK & Hong Kong & Hang Seng Index & $12 / 31 / 86$ & 6122 \\
\hline IDN & Indonesia & Jakarta Composite Index & $07 / 01 / 97$ & 3439 \\
\hline IND1 & India & BSE 30 Index & 07/01/97 & 3497 \\
\hline IND2 & India & S\&P CNX NIFTY Index & $08 / 12 / 02$ & 2262 \\
\hline ISR & Israel & TA-100 Index & 07/01/97 & 2972 \\
\hline ITA & Italy & FTSE MIB Index & $06 / 02 / 03$ & 2115 \\
\hline JPN & Japan & Nikkei 225 Index & $01 / 04 / 84$ & 6795 \\
\hline KOR & Korea & Seoul Composite Index & 07/01/97 & 3486 \\
\hline MEX & Mexico & IPC Index & $11 / 08 / 91$ & 4945 \\
\hline MYS & Malaysia & KLSE Composite Index & $12 / 03 / 93$ & 4376 \\
\hline NLD & The Netherlands & AEX General Index & $10 / 12 / 92$ & 4805 \\
\hline NOR & Norway & OSE All Share Index & $02 / 07 / 01$ & 2650 \\
\hline NZL & New Zealand & NZSE 50 Index & $04 / 30 / 04$ & 1819 \\
\hline OIL1 & - & New York Crude Oil Price & $10 / 01 / 28$ & 6560 \\
\hline OIL2 & - & North Sea Brent Crude Oil Price & $01 / 28 / 30$ & 6155 \\
\hline RUS & Russia & RTS Index & 09/01/95 & 3983 \\
\hline SGP & Singapore & Straits Times Index & $12 / 28 / 87$ & 5919 \\
\hline SWE1 & Sweden & Stockholm General Index & $01 / 08 / 01$ & 2731 \\
\hline SWE2 & Sweden & OMXS 30 Index & 07/06/04 & 1820 \\
\hline TUR & Turkey & ISE 100 Index & 01/04/88 & 5887 \\
\hline TWN & Taiwan & Taiwan Weighted Index & $07 / 02 / 97$ & 3480 \\
\hline USA1 & USA & Dow Jones Industrial Average Index & $10 / 01 / 28$ & 20817 \\
\hline USA2 & USA & NASDAQ Composite Index & $02 / 05 / 71$ & 10229 \\
\hline USA3 & USA & S\&P 500 Index & $01 / 03 / 50$ & 15510 \\
\hline USA4 & USA & 13-WEEK TREASURY Bill & $01 / 04 / 60$ & 12901 \\
\hline USA5 & USA & CBOE Interest Rate 10-year T-Note & $01 / 02 / 62$ & 12405 \\
\hline USA6 & USA & Treasury Yield 30 Years & $02 / 15 / 77$ & 8633 \\
\hline USA7 & USA & Treasury Yield 5 Years & $01 / 02 / 62$ & 12402 \\
\hline
\end{tabular}

The aggregate series codes are used next to refer to the 37 individual major stock market indexes and seven other measures shown in the table. The sample includes occasional holidays and excludes all Saturdays and Sundays. The gold (GOL) series data is from The World Gold Council; the two crude oil prices (OIL1 and OIL2) are from the Federal Reserve Bank of St. Louis' FRED Database. All other data are from the US and UK Yahoo! Finance websites. 
unit root tests, and for the pairwise cointegration test, the procedure is for a VAR of order $p$

$$
y_{t}=A_{1} y_{t-1}+\cdots+A_{p} y_{t-p}+B x_{t}+\epsilon_{t}
$$

Here $y_{t}$ is a $k$-vector of non-stationary $I(1)$ variables, $x_{t}$ is a $d$ vector of deterministic variable, and the error term is a vector of innovations. Using the first-order difference form, the VAR can be rewritten as

$$
\Delta y_{t}=\Pi y_{t-1}+\sum_{i=1}^{p-1} \Gamma_{i} \Delta y_{t-i}+B x_{t}+\epsilon_{t}
$$

where

$$
\Pi=\sum_{i=1}^{p} A_{i}-I, \quad \Gamma_{i}=-\sum_{j=i+1}^{p} A_{j} .
$$

If the coefficient matrix $\Pi$ has reduced rank $r<k$, then there exists $k \times r$ matrices $\alpha$ and $\beta$ each with rank $r$ such that $\Pi=\alpha \beta^{\prime}$ and $\beta^{\prime} y_{t}$ is $I(0), r$ is the number of cointegrating relations or the rank. The voluminous output is available from the authors by request.

All the Granger causality tests are based on the opening and closing sequences of the global equity markets. These sequences are exhibited in Table A.3 and Table A.4. These two figures are used to exclude the illogical causality regressions, such as the relation from the current day closed level of the equity index in Italy to that of the Malaysian market, which closes earlier, or the current day causal relation from the closed level of the DAX index to the open level of the Mexican market, which has already opened when the German market stopped its operation.

In Table A.3, we show each market's opening time within a calendar day and order them from the earliest to the latest. Getting the opening order correct is necessary for our tests of causality among opening values, because such a test is meaningful only under the assumption that the earlier opening markets may affect the open levels of the later opening markets but not the reverse. We then reorder the markets according to their closing times in Table A4, and, as with opening times, the ordering is necessary because it is only reasonable to assume that the earlier closed of a market may affect the closed levels of the later closing markets.

By setting the US market as the base, the earliest market that starts to trade on the same calendar date is New Zealand, and the same calendar day trade ends in the world when the markets in Brazil, Mexico, Canada, and the United States closed. There is a one-hour gap between when the last markets closed and when the first markets open on the next day.

The causality tests are used to examine the efficient market hypothesis. The weak-form EMH is violated if the historical market levels affect the current and future market levels. Strictly defined, the aggregate hypothesis tested in our paper is stated as follows.

$\mathrm{H}_{0}$ : Historical information is useless in forecasting the future price.
$\mathrm{H}_{\mathrm{a}}$ : Exploring historical information can help forecast the future price.

Specifically, we test the weak-form EMH by breaking this hypothesis into three subcategories. First, we test the information digestion effect. If the market is efficient, then it should incorporate all the available information fully and instantly. There should be no time for the market to absorb, analyze, and reflect historical information. If the market needs to gradually, instead of instantly, incorporate valuable information and reflect such information in the future market level trend, arbitrage opportunities will exist. Strictly defined, the hypothesis of the first group test (information digestion) is stated as follows.

$\mathrm{H}_{0}$ : Financial markets instantly incorporate and reflect historical information.

$\mathrm{H}_{\mathrm{a}}$ : Financial markets only gradually incorporate and reflect historical information.

Second, we test for cyclical patterns of historical impact. If the old information cannot only affect the current market, but can also influence the market in a recursive manner, the hypothesis of market memory is proved, further discrediting the EMH. Strictly defined, the hypothesis of the second group test is stated as follows.

$\mathrm{H}_{0}$ : Financial markets remember information and recall it recursively and periodically.

$\mathrm{H}_{\mathrm{a}}$ : Historical impacts can only affect the current market once.

Third, we test for the existence of market leaders. If there exist market leaders for global indexes and they have significant impacts on the trends of other indexes, this is regarded as a further violation of the weak-form $\mathrm{EMH}$, since the EMH holds only when no other markets' historical levels can be used to forecast the future trend. Strictly defined, the hypothesis of the third group test is stated as follows.

$\mathrm{H}_{0}$ : No global equity markets leader exists.

$\mathrm{H}_{\mathrm{a}}$ : One or more global equity market leaders exist.

To construct our Granger causality tests we regress each index's daily open, high, low, closed, and volume $(\mathrm{O} / \mathrm{H} / \mathrm{L} / \mathrm{C} / \mathrm{V})$ series in 30-day windows on the lagged values of the series and on the lagged values of each of the other index series. Since we have five series for each of the 37 indexes, we regress the total of 185 series on each of the other 184 series so the total number of pairwise regressions for just the indexes is 34,040 . From the outputs of the pairwise Granger causality regressions, we compute the average probabilities of causality relations from an index to all other indexes on a 30 -day daily basis.

We first estimate the pairwise causality regressions. Next we assign a 1 to regressions which identify the existence of a significant Granger causality relation and assign a 0 to insignificant results. The third step is to compute the average probabilities of existing relation for the affecting variables across indexes and rerank the probabilities with different 
TABLE 2: The impact of time on the historical influence of global financial markets.

\begin{tabular}{lccccc}
\hline \multirow{2}{*}{ Series of causality } & \multicolumn{3}{c}{ Equation (5) regression } & \multicolumn{3}{c}{ Equation (6) regression } \\
& Intercept & Slope & $R^{2}$ & Intercept & Slope \\
\hline INDEX to INDEXC & 0.2640 & -0.0003 & 0.2820 & 0.2443 & -0.0022 \\
INDEX to INDEXO & 0.3461 & -0.0057 & 0.3266 & 0.2908 & -0.0032 \\
INDEX to INDEXH & 0.3207 & -0.0048 & 0.3522 & 0.2787 & -0.0030 \\
INDEX to INDEXL & 0.3234 & -0.0058 & 0.4289 & 0.2834 & -0.0041 \\
INDEX to INDEXV & 0.4628 & -0.0013 & 0.1653 & 0.4449 & -0.0004 \\
\hline
\end{tabular}

The results are the OLS outputs of (5) and (6). The regression lines examine the attenuation of impact of the historical information. INDEX variable implies the world financial market. INDEXC/O/H/L/V refers to the close, open, high, low, and trading volume levels of the global markets. The statistical significance level of Granger causality test is $P<0.05$.

lagged days; in the fourth step, within the 30-day window, we find the peaks of the average probabilities in the potential cycles. The average probability at a certain day $t$, the $P_{t}$, is defined as the peak of the cycle if one of the following two conditions is met.

$$
\begin{aligned}
& \text { Condition 1: } P_{t}>P_{t-1} \text {, and } P_{t-1}>(1+5 \%) P_{t-2} . \\
& \text { Condition 2: } P_{t}>(1+5 \%) P_{t-1} \text {, and } P_{t-1}>P_{t-2} .
\end{aligned}
$$

These two conditions can capture the peaks at a length of at least three days' probability consistent changes. The fifth step is to compute the probability of being a peak of the cycles of average probabilities of existing causality relations, and the computation is made on three different significance levels.

To examine the extent of an information digestion effect, we perform regressions to test for the change in the average proportions of significant causality relations against the degeneration of dates. We first employ augmented unit root tests to justify any existing nonstationary time series. By first-order differencing of the variables with unit roots, we further conduct the following regression to avoid violating the ordinary least square regression assumption. The results of unit root tests are available by request. The regression equation is

$$
\operatorname{SIGCAU}_{j}^{i}=\beta_{(0 \mid j)}^{i}+\sum_{k} \beta_{(1 \mid j)}^{i} \mathrm{DATE}+\varepsilon_{j}^{i} .
$$

In this regression, the dependent variable, SIGCAU, is the average proportions of significant causality relations, $i$ identifies the different series being affected (closed, open, high, low, or volume), and $j$ identifies the significance levels $(P<0.01, P<0.05$, and $P<0.1)$. The independent variables, DATE, include the 31 days from the current operating day to 30 operating days ago. This regression tests whether the power of historical information will weaken as the information becomes older. The results are presented in Table 2.

However, this impact reduction might be largely caused by the sharp first day decline. To verify this hypothesis, we update the regression of (5) to the following regression:

$$
\operatorname{SIGCAU}_{j}^{i}=\beta_{(0 \mid j)}^{i}+\sum_{k} \beta_{(1 \mid j)}^{i} \operatorname{LAGDATE}+\varepsilon_{j}^{i} .
$$

In (6), all the definitions of the variables are the same as (5) except the independent variable, LAGDATE. This variable only contains 30 observations, which are the 30 lagged days, and excludes the current operating day. This regression is performed to test whether the decline of historical information with date, even though being insignificant, is caused by the first day decline. The results are also combined in Table 2 . The next chapter will show that the impacts measured in different statistical significance levels are similar for all the five series: closed, open, intraday high, intraday low, and volume. Tests not reported here show that the differences in the average probabilities in the three statistical levels do not change in a deterministic pattern.

\section{Results and Discussion}

The results after the first three steps discussed above are presented in Figure 1 and Table 2, and the cyclical patterns computed from steps four and five are exhibited in Figure 2. Figure 1 shows the attenuation of the impact of historical information in the world financial market in the 30-day test window. We adopt the probability of the existence of causal relations between historical performance and current equity prices. The decrease of such probability, or attenuation, can be explicitly quantified compared to other integration models. The results provide straightforward evidence of the violation of the weak-form EMH. Though the probabilities of significant Granger causalities existing decrease as the historical information ages in the 30-day window, the impact of historical public information is persistent, for all types (open, closed, high, low, and volume levels) of affected indexes.

As shown in Figure 1, the open and closed levels of the global markets are affected by the historical levels of other international markets significantly. The current day peer markets have the strongest impact, and this influence decreases dramatically after the current day information degenerates to the information from one day ago. Then from the -1 day lag to -30 day lag, the probabilities of significant Granger causality no longer decrease in a consistent style. Fluctuations of probabilities exist, and an apparent cyclical period of approximately 14 days can be observed. This cyclical pattern will be identified in Figure 2. In addition, the impacts from the global market to world closed and open levels are similar.

The intraday high and low levels of the global markets are also affected by the historical levels of other markets 


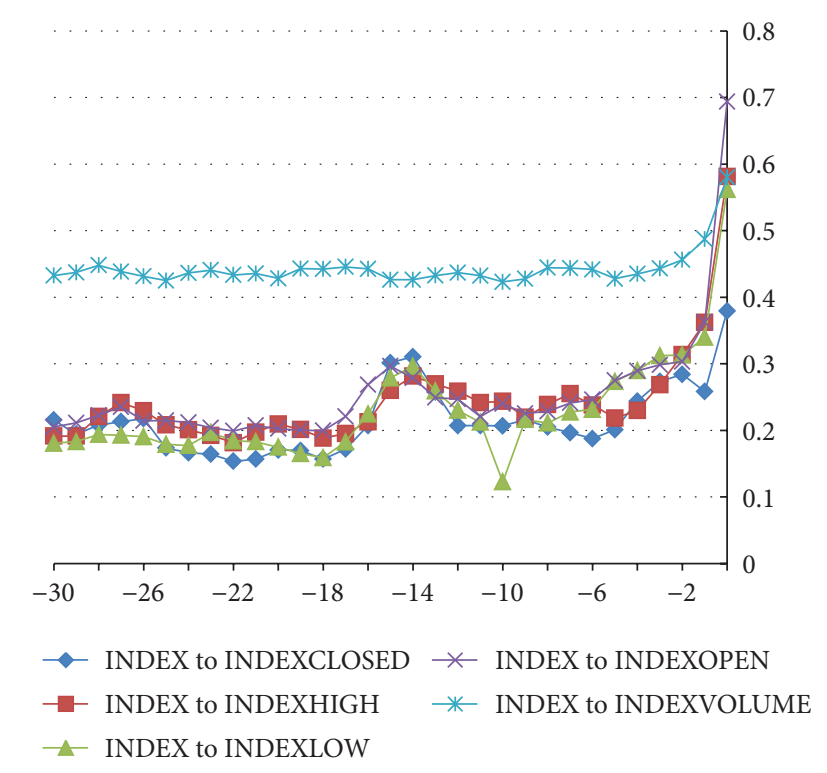

FIGURE 1: The historical impact attenuation from world major indexes to the closed, open, high, low, and volume levels of world markets in a 30-day window. The INDEX variable implies the world financial market. The horizontal axis is the dates in the test window. date $=0$ is the current period; date $=-1 \cdots-30$ are the lagged operating days. If date $=0$ refers to August 1 , then Date $=-2$ refers to July 30. The vertical axis refers to the average proportion of existing causality relations at $P<0.05$ significance level.

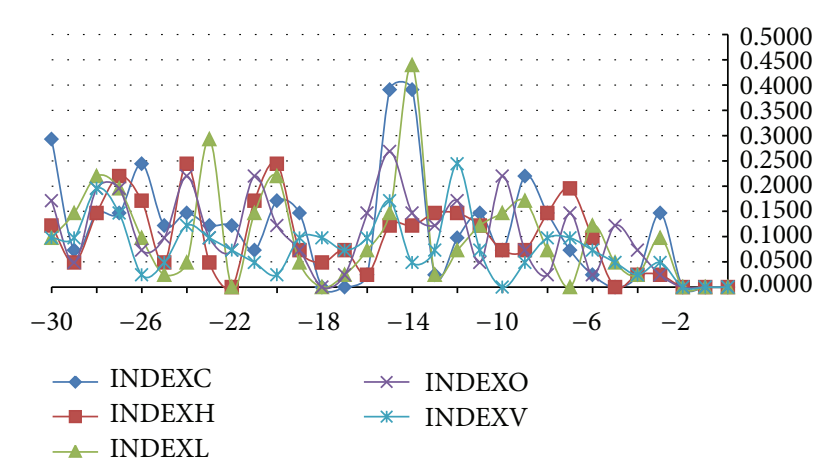

FIGURE 2: The probability distribution of being the most influential day(s) on daily levels of world market indexes within 30 lagged operating days. The INDEX variables imply the average impact from the world financial market to its $\mathrm{C} / \mathrm{H} / \mathrm{L} / \mathrm{O} / \mathrm{V}$ levels across markets. The horizontal axis is the dates in the test window. The statistical significance level of Granger causality test is $P<0.05$.

significantly. Again, the current day peer markets have the strongest impact, and then the probability of existing Granger causalities decreases greatly after the current day information becomes less fresh. Then from the 1-day lag to the 30-day lag, the probabilities of significant Granger causality no longer decrease in a consistent style. However, obvious fluctuations and cyclical periods of approximately 14 days can only be observed in the intraday high series but not in the low series.
The attenuation process of the impact from historical market information to market trading volume is very different from such impacts to market closed, open, intraday high, and intraday low, as demonstrated in Figure 1. First, even though the current peer markets still have the strongest impact, the probability of existing Granger causalities does not decrease much after the current day information becomes less fresh; second, obvious fluctuations and cyclical periods of approximately 5 days can be observed; third, the historical information maintains a relatively high impact even after four weeks.

Consistent with Figure 1, Table 2 implies that the historical influences are not significantly affected by how old the historical information is. Generally the slopes are negative, implying that as information flows become less fresh, their influences on the global markets decline.

A comparison of the results from the two regression equations can lead to the following conclusions: first, when the current day causality probability is excluded from the regression, the regression trend line is much flatter; second, the regression result is still insignificant, and the $R^{2}$ is not consistently changed in the second regression. These conclusions support the hypothesis that impact reduction might be largely caused by the sharp first day decline. After the current day, the impact attenuation almost disappears in all five series. This is consistent with the cyclical pattern of impact we observe in Figure 2.

We have constructed attenuation regressions (simple trends) for each of the individual series of the single indexes in each market and have searched for attenuation "anomalies." An anomaly is defined as the existence of at least one historical impact on a certain date in the 30-day test window that is higher than the impact of the current day market level. This phenomenon is an indicator of an inefficient market, because no historical information should be more influential than the current relevant information. All of the series of trading volumes have an abnormality, and half of the open levels of the markets also carry this abnormality, most of which are from Asia and other developing economies, which is a possible sign of immature markets. Very few anomalies can be detected in the high/low/closed series.

We find significant cyclical patterns in the impacts of the world's major indexes in the 30-day window on the closed levels of the world's major indexes, as shown in Figure 2. The first peak occurs 3 days prior to the current operating day. Thereafter, the peak will appear repeatedly approximately every 5.5 lagged operating days. This figure implies that historical market levels have a persistent impact on the current world major financial indexes. The financial markets have a strong memory effect: the past information from other markets, especially information from 5 to 6 days ago, will affect the instant closed levels of world markets. This effect functions in the market in a recursive way: the current level is affected by the level 5.5 days ago, and the latter is affected by the market level from another 5 to 6 days ago, which is 11 days from the present. The effect is consistent from the 3 lagged days and is spread to date -9 , date -15 , date -20 , date -25 , and date -30 . 
The cyclical pattern of the impact of historical information conveyed from world major indexes on the intraday highest level of the world major indexes is not highly significant, even though certain periodical peak and bottom waves can still be identified. A plausible explanation is that the intraday highest level in each market is more stochastic than the closed level of the market. Perhaps because it is representative of optimistic investors' incentives, the market high may be more affected by domestic information and investor expectations within the operating day, rather than being affected by international information from historical data.

The cyclical impact to the intraday lows of the world indexes is significant as indicated in Figure 2. This inconsistent result shows that the current world financial market levels are affected by the optimistic and pessimistic historical information in an asymmetric way. Markets may remember the bad news and ignore the good news. Consistent with Figure 1 which indicates the impact to the closed levels of world markets, the period of the cycle is approximately 5.5 days, and the impact is persistent in a recursive way.

The cyclical pattern of the impact of the world market to the open levels is significant. The period length is lower than for the impacts to the closed levels of global markets. The higher frequency of impacts may be explained by more time being required for the information to be digested by global investors. In Figure 1, the impact of global market historical information on the global market closed level may be weaker because closed levels are more affected by domestic intraday information. However, after having an overnight for interpretation and digestion of information, the open levels of world financial markets are more sensitive to the outsiders' information, which may be an important message for analysis of global markets.

A rich literature confirms the causality of trading volume and equity returns, for example, Gebka and Wohar [29]. Figure 2 further shows that such causality does not present a cyclical pattern, and this conclusion is consistent with the fundamental economic principles. Trading volume is primarily determined by the supply of liquid funds, assuming that the demand for funds is elastic. Therefore, it is unreasonable to believe that patterns of constraints on available funds will appear periodically in a very short 30-day window. However, [30], among others, support the existence of world business cycles, and there are obviously periods of shortages of funds; however, these periods are much longer than our study window. To summarize, the results from Figure 2 reject the null hypothesis of the second group test, and we reject the weak-form EMH as historical information is highly influential.

Observed from Figure 2, the different patterns of the four series, that is, the inconsistent first half of the test window compared with the synchronous second half of the test window, imply the different treatment to various types of information in terms of the investors. For older information, because of the anchoring bias [31], investors consistently treat the information no matter from which category, it is the open, closed, intraday high, or intraday low. However, in terms of the fresh news that is generated within two weeks, the four series in the global markets are affected by the international markets in a stochastic way, and this is because the anchoring biases of the investors have not formed yet. In fact, which series is more affected by the fresh news is largely determined by the features of the news itself, for example, how pessimistic the news is.

We perform similar peak seeking procedure at different significance levels of $P<0.01$ and $P<0.10$ as robustness test. The results are available upon request. A panel regression using different statistical criteria does not affect the conclusion of peak impact detection and the measure of the length of cyclical periods. However, it will affect the result of comparison among different market series. The less strict the criterion is, the more obvious the synchronous peak patterns are.

If the global financial market is at least weak-form efficient, then no global market or regional market leaders should exist in security markets. The market leader is defined as an index that can significantly and unilaterally affect other indexes with an insignificant feedback. To identify market leaders, we rank the average amount of significant causality results. Though simple counts are the standard treatment, they do not fit the data fact in our study because of the uneven sample sets. Thus we use the average percentages. Table 3 indicates the rankings of average significant causality relations across the test window and across the $\mathrm{C} / \mathrm{H} / \mathrm{L} / \mathrm{O} / \mathrm{V}$ series for indexes.

Table 3 compares impacts across indexes. If the weakform efficient market hypothesis holds, then the percentage of significant causal relations for all indexes should be zero. Furthermore, if the impacts of historical information across markets are uneven, that is, market leaders exist, then there is even stronger evidence of violation of the EMH. Our results show that such evidence is significant and robust.

Ranked at the significance level of $P<0.05$, the average proportion of significant impacts from the 44 indexes, including equity, bond, and commodity markets, varies from 0.52 to 0.11 . The indexes that are most influential (Tier 1) are the crude oil price in New York, the crude oil price of North Sea Brent, the equity markets in Mexico, Turkey, Australia, Russia, Germany, and Sweden, the Dow Jones index from the U.S. and Hong Kong, and the world gold price. Obviously, the commodity markets are the market leaders, and there are several regional leaders: the U.S. and Mexico in America, Germany in Europe, Australia and Hong Kong in Asia, and Turkey in the Middle East. The result of the strong impact from Russian equity market can be regarded as an extension of the strong impacts of the oil prices, because the RTS index in Russia is closely tied to its domestic crude oil industry. These market leaders affect the global financial markets very significantly, and their historical returns can be used as indicators of the future trends of the markets. The null hypothesis of the third group test is rejected. This conclusion is robust in terms of the different statistical criteria.

All the above results in this paper reject the aggregate null hypothesis described in the Introduction, which states that historical information cannot be used to forecast future prices in the world major financial markets. 
TABLE 3: Rankings of global financial market major indexes on average significant causality.

\begin{tabular}{|c|c|c|}
\hline Rank & Index & PCAGM \\
\hline 1 & OIL1 & 0.5239 \\
\hline 2 & OIL2 & 0.4690 \\
\hline 3 & MEX & 0.4112 \\
\hline 4 & TUR & 0.3949 \\
\hline 5 & AUS & 0.3837 \\
\hline 6 & RUS & 0.3798 \\
\hline 7 & DEU & 0.3793 \\
\hline 8 & SWE1 & 0.3735 \\
\hline 9 & USA1 & 0.3733 \\
\hline 10 & HGK & 0.3732 \\
\hline 11 & GOL & 0.3709 \\
\hline 12 & AUT & 0.3574 \\
\hline 13 & USA3 & 0.3412 \\
\hline 14 & USA4 & 0.3403 \\
\hline 15 & IND1 & 0.3231 \\
\hline 16 & SWE2 & 0.3060 \\
\hline 17 & IDN & 0.3054 \\
\hline 18 & SGP & 0.3051 \\
\hline 19 & GBR & 0.3048 \\
\hline 20 & $\mathrm{CHN}$ & 0.2933 \\
\hline 21 & $\mathrm{CHE}$ & 0.2915 \\
\hline 22 & KOR & 0.2879 \\
\hline 23 & CHL & 0.2785 \\
\hline 24 & ARG & 0.2706 \\
\hline 25 & USA2 & 0.2697 \\
\hline 26 & FRA & 0.2600 \\
\hline 27 & USA7 & 0.2555 \\
\hline 28 & IND2 & 0.2546 \\
\hline 29 & BRA & 0.2415 \\
\hline 30 & BEL & 0.2362 \\
\hline 31 & USA5 & 0.2268 \\
\hline 32 & USA6 & 0.2210 \\
\hline 33 & ESP2 & 0.2197 \\
\hline 34 & ISR & 0.2143 \\
\hline 35 & NLD & 0.2132 \\
\hline 36 & MYS & 0.2116 \\
\hline 37 & CAN & 0.2060 \\
\hline 38 & NOR & 0.2026 \\
\hline 39 & TWN & 0.1873 \\
\hline 40 & NZL & 0.1858 \\
\hline 41 & DNK & 0.1812 \\
\hline 42 & ESP1 & 0.1759 \\
\hline 43 & ITA & 0.1237 \\
\hline 44 & JPN & 0.1107 \\
\hline
\end{tabular}

The ranking is based on the average percentage of significant causality relations as a result of the Granger causality tests at $P<0.05$ level. For each of the indexes, we rank the average amount of significant causal relations. The arithmetic average is computed across different series of an index and all the outputs in the 30-day test window. PCAGM refers to the probability and capability of affecting global market of a certain financial index.

\section{Conclusion}

In this paper we study the causal relations between the cross-country and cross-market historical levels of global financial markets and their current market levels. The primary purpose is to identify the impact of the historical levels of the major indexes in order to test the weak-form EMH. We test the causal relations among 44 indexes from global financial markets in a 30-day window and explore the significant influence of lagged information; then we examine the cyclical pattern of the impacts from pervious market transactions and the information digest hypothesis; in addition, this paper identifies the leaders in financial markets.

The Granger causality model is employed to measure the first moment levels in the markets rather than the cointegration tests or various ARCH models, because causality tests have a richer set of impacts than cointegration and are better in the measuring of nonvolatility contagion. We use the daily data from 37 world famous equity market indexes across 32 countries; each one includes the daily open, closed, high, low and volume series, 3 major commodity price indexes, and 4 money market return indexes with different terms.

The results of the causality tests and relevant regressions in this paper show the existence of the persistent and cyclical impacts of global markets' historical levels on their current performances. The regression outputs first reject the hypothesis that historical information cannot be used to forecast the future market levels; then this paper shows that the impact of historical information does not strictly decrease across time, and this conclusion rejects the intuition of the information digestion effect.

Results of the causality tests reveal that, except for a sharp decrease in the power of the impact from the current day information to the one-day-lagged information, such decrease disappears after the first lagged operating day. In fact, all the 30 operating days in the test window indicate a cyclical pattern in their impacts. The cyclical pattern of impacts on the market closed levels has a period of 5.5 operating days on average, implying that the financial market will recall the past information recursively. Similar conclusions apply to the market open, high, and low levels, but not to the trading volume levels.

In addition, this paper identifies the global and regional financial market leaders. Such leaders generate a persistent influence on the future trends of global markets and therefore provide longer term evidence of EMH violations.

This research can be extended in three ways: first, enlarge the dataset to incorporate more money market and commodity data and increase the data frequency to check the robustness of the current conclusion; second, include the impacts of macroeconomic data into the tests to dilute the existing endogeneity problem; third, extend the test window to 60 days or even longer to detect the midterm and long term impact cycles. These steps are restricted currently by the data and computation availability. 


\section{Endnotes}

1. A very large number of comparisons between the results of our paper and those in the prior literature are available from authors on request.

2. A time series $X$ Granger causes $Y$, if it can be shown, through the linear regression of the current value of $Y$ on the lagged values of $X$ and the lagged values of $Y$ that the coefficients of the lagged $X$ values are statistically significant in an $F$ test. A correlation coefficient is defined as

$$
\rho_{X, Y}=\frac{\operatorname{Cov}(X, Y)}{\sqrt{\operatorname{Var}(X)} \cdot \sqrt{\operatorname{Var}(Y)}} .
$$

Clearly whether or not $\rho_{X, Y}=0$ (whether there is a significant correlation) is not related to the lagged values of $X$ and is therefore the contemporaneous correlation of $X$ and $Y$ instead of causality. Note that causality is only implied by regression significance between the current value of one variable and the past values of others. Granger causality implies, but does not prove, that movements of one variable cause movements of another.

3. The entire procedure is repeated three times for significance levels for rejecting the hypothesis of no causality of $P<0.01, P<0.05$, and $P<0.10$. In this paper, however, we only report the significance level of $P<0.05$, and the entire results are available upon request.

4. The more than 200 attenuation regressions in chart form will be sent by the authors on request.

\section{References}

[1] E. Fama, "Efficient capital markets: a review of theory and empirical work," The Journal of Finance, vol. 25, no. 2, pp. 383$417,1970$.

[2] J. E. Engelberg and C. A. Parsons, "The causal impact of media in financial markets," The Journal of Finance, vol. 66, no. 1, pp. 67-97, 2011.

[3] C. G. Glimore, M. G. McManus, R. Sharma, and A. Tezel, "The dynamics of gold prices, gold mining stock prices and stock market prices comovements," Research in Applied Economics, vol. 1, no. 1, pp. 1-19, 2009.

[4] I. Karunanayake, A. Valadkhani, and M. O’Brien, "Financial crises and international stock market volatility transmission," Australian Economic Papers, vol. 49, no. 3, pp. 209-221, 2010.

[5] K. Phylaktis and L. Xia, "Equity market comovement and contagion: a sectoral perspective," Financial Management, vol. 38, no. 2, pp. 381-409, 2009.

[6] J. Tavares, "Economic integration and the comovement of stock returns," Economics Letters, vol. 103, no. 2, pp. 65-67, 2009.

[7] A. Rua and L. C. Nunes, "International comovement of stock market returns: a wavelet analysis," Journal of Empirical Finance, vol. 16, no. 4, pp. 632-663, 2009.

[8] J. L. M. Marcelo, J. L. M. Quirós, and M. D. M. Quirós, "Asymmetric variance and spillover effects. Regime shifts in the Spanish stock market," Journal of International Financial Markets, Institutions and Money, vol. 18, no. 1, pp. 1-15, 2008.
[9] M. Beine, A. Cosma, and R. Vermeulen, "The dark side of global integration: increasing tail dependence," Journal of Banking and Finance, vol. 34, no. 1, pp. 184-192, 2010.

[10] C. S. Savva, "International stock markets interactions and conditional correlations," Journal of International Financial Markets, Institutions and Money, vol. 19, no. 4, pp. 645-661, 2009.

[11] S. Dees, F. Di Mauro, M. H. Pesaran, and L. V. Smith, "Exploring the international linkages of the euro area: a global var analysis," Journal of Applied Econometrics, vol. 22, no. 1, pp. 1-38, 2007.

[12] M. Eryiǧit and R. Eryiǧit, "Network structure of crosscorrelations among the world market indices," Physica A, vol. 388, no. 17, pp. 3551-3562, 2009.

[13] B. H. Boyer, "Style-related comovement: fundamentals or labels?” The Journal of Finance, vol. 66, no. 1, pp. 307-332, 2011.

[14] F. Jawadi, M. E. H. Arouri, and D. K. Nguyen, "Stock market integration in the Euro area: segmentation or linear modeling misspecification," International Journal of Business, vol. 15, no. 3, pp. 307-317, 2010.

[15] L. Cappiello, R. F. Engle, and K. Sheppard, "Asymmetric dynamics in the correlations of global equity and bond returns," Journal of Financial Econometrics, vol. 4, no. 4, pp. 537-572, 2006.

[16] A. Valadkhani and S. Chancharat, "Dynamic linkages between Thai and international stock markets," Journal of Economic Studies, vol. 35, no. 5, pp. 425-441, 2008.

[17] C. Morana and A. Beltratti, "Comovements in international stock markets," Journal of International Financial Markets, Institutions and Money, vol. 18, no. 1, pp. 31-45, 2008.

[18] T. Syriopoulos, "Dynamic linkages between emerging European and developed stock markets: has the EMU any impact?" International Review of Financial Analysis, vol. 16, no. 1, pp. 4160, 2007.

[19] J. Ammer and J. Mei, "Measuring international economics linkages with stock market data," The Journal of Finance, vol. 51, no. 5, pp. 1743-1763, 1996.

[20] G. Bekaert and C. R. Harvey, "Time-varying world market integration," The Journal of Finance, vol. 50, no. 3, pp. 403-444, 1995.

[21] F. Climent and V. Meneu, "Has 1997 Asian crisis increased information flows between international markets?" International Review of Economics and Finance, vol. 12, pp. 111-143, 2003.

[22] A. C. Worthington, M. Katsuura, and H. Higgs, "Price linkages in Asian equity markets: evidence bordering the Asian economic, currency and financial crises," Asia-Pacific Financial Markets, vol. 10, no. 1, pp. 29-44, 2003.

[23] J. Wongswan, "Transmission of information across international equity markets," Review of Financial Studies, vol. 19, no. 4, pp. 1157-1189, 2006.

[24] C. S. Hakkio and M. Rush, "Cointegration: how short is the long run?” Journal of International Money and Finance, vol. 10, no. 4, pp. 571-581, 1991.

[25] C. Morana, "International stock markets comovements: the role of economic and financial integration," Empirical Economics, vol. 35, no. 2, pp. 333-359, 2008.

[26] A. Z. Baharumshah, T. Sarmidi, and H. B. Tan, "Dynamic linkages of Asian stock markets: an analysis of pre-liberalization and post-liberalization eras," Journal of the Asia Pacific Economy, vol. 8, no. 2, pp. 180-209, 2003.

[27] W. N. Goetzmann, L. Li, and K. G. Rouwenhorst, "Long-term global market correlations," Journal of Business, vol. 78, no. 1, pp. 1-37, 2005. 
[28] W. J. Granger, "Investigating causal relations by econometric models and cross-spectral methods," Econometrica, vol. 37, no. 3, pp. 424-438, 1969.

[29] B. Gebka and M. E. Wohar, "Causality between trading volume and returns: evidence from quantile regressions," International Review of Economics and Finance, vol. 27, pp. 144-159, 2013.

[30] R. Næs, J. A. Skjeltorp, and B. A. Ødegaard, "Stock market liquidity and the business cycle," The Journal of Finance, vol. 66, no. 1, pp. 139-176, 2011.

[31] S. D. Campbell and S. A. Sharpe, "Anchoring bias in consensus forecasts and its effect on market prices," Journal of Financial and Quantitative Analysis, vol. 44, no. 2, pp. 369-390, 2009. 

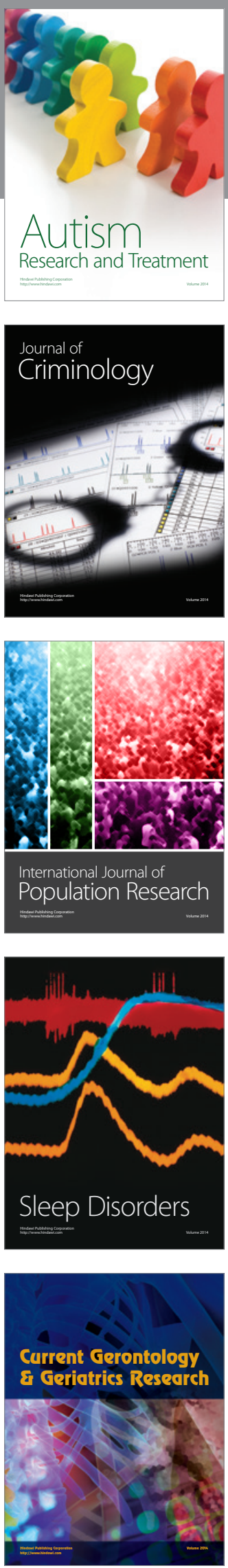
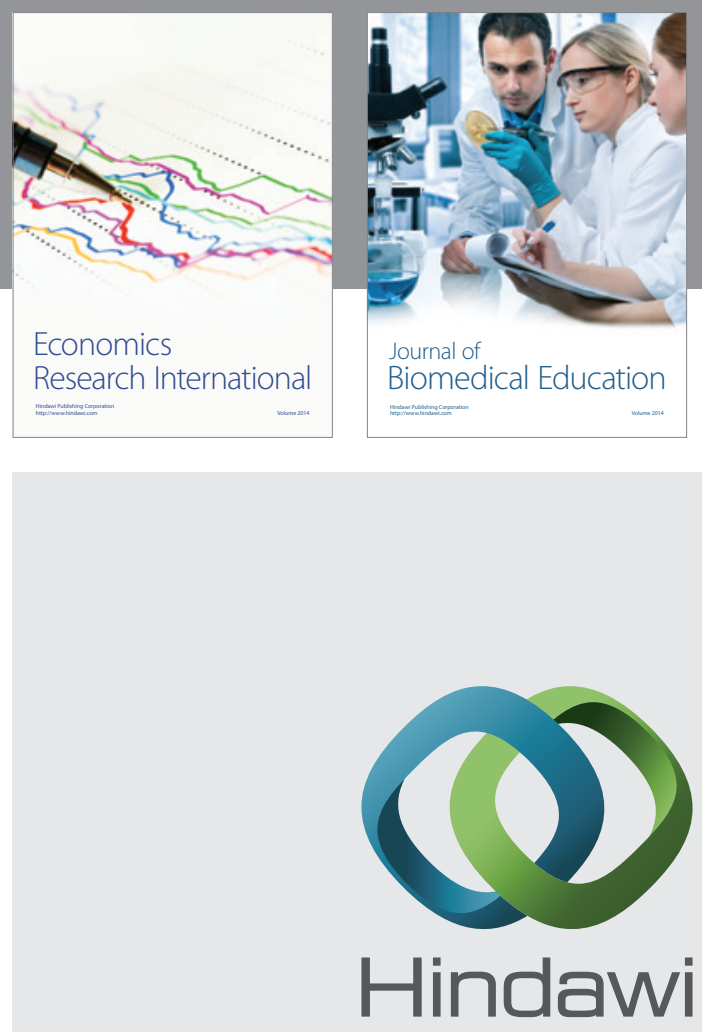

Submit your manuscripts at

http://www.hindawi.com
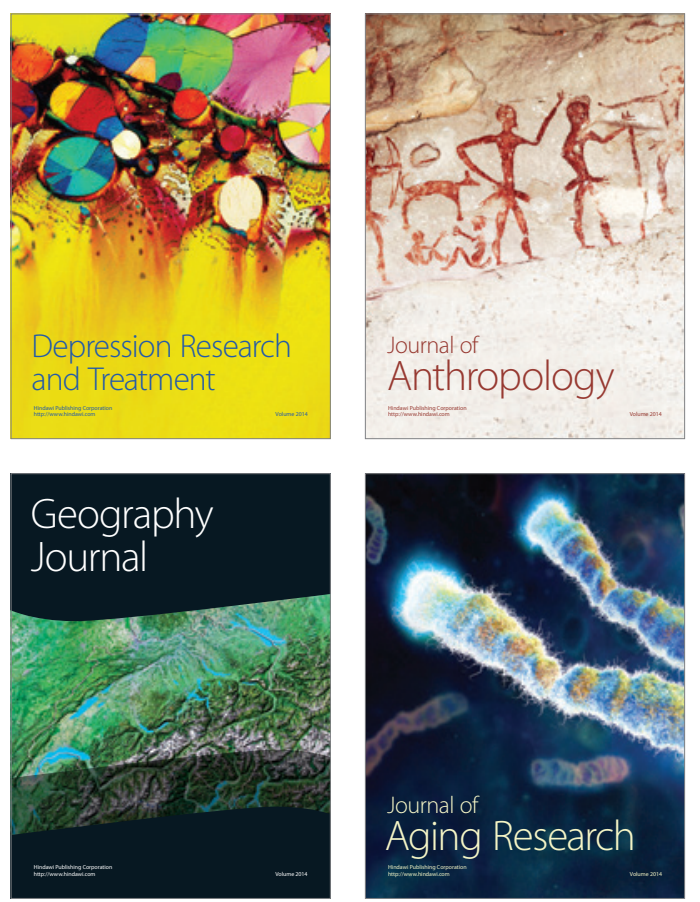
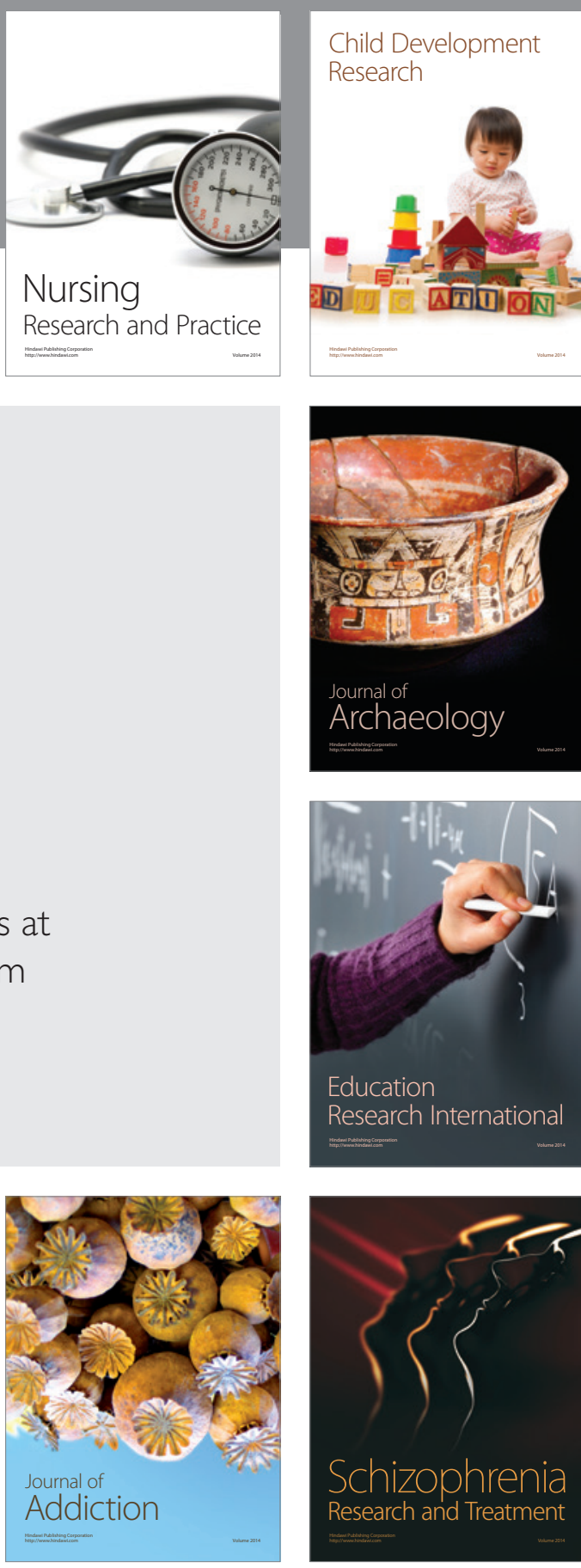

(D)
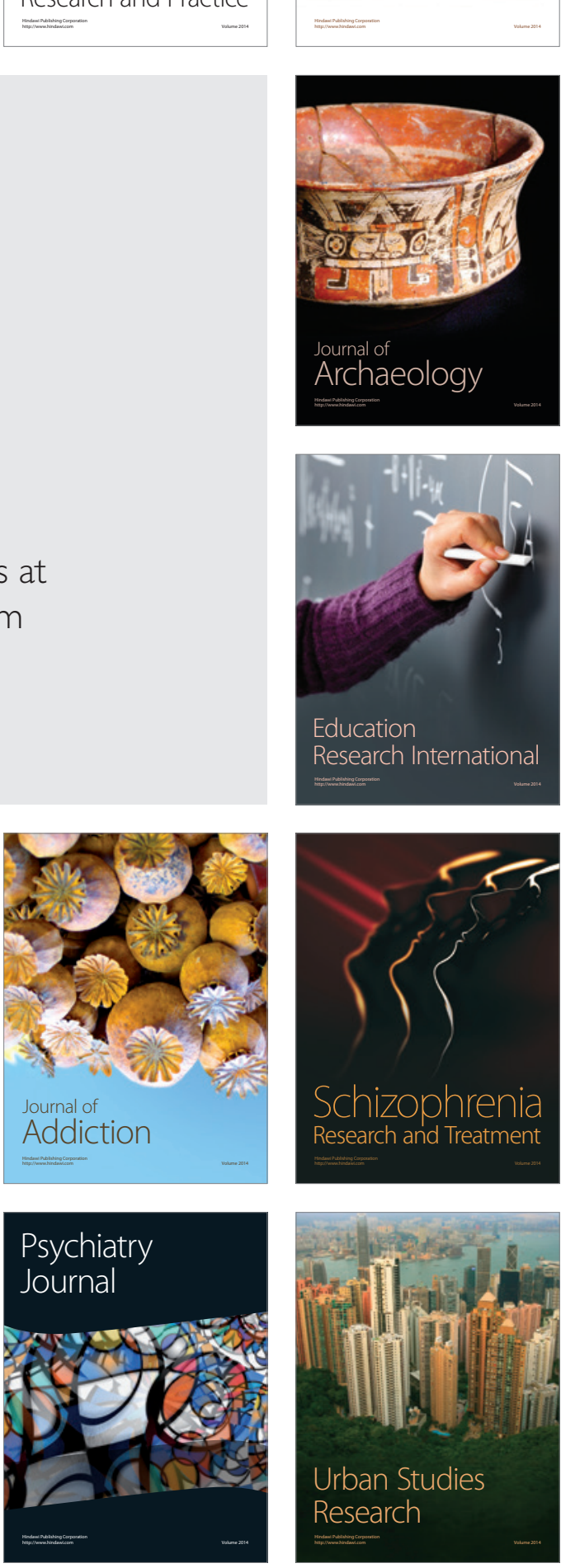